\title{
Vaginal delivery by Duhrssen's incision in a case of uterine prolapse
}

\section{Ankita Chakraborty*, Bandana Shyam Gohain}

Department of Obstetrics and Gynaecology, Silchar Medical College, Silchar, Assam, India

Received: 10 December 2020

Accepted: 16 January 2021

\section{*Correspondence:}

Dr. Ankita Chakraborty,

E-mail: ankita4206@gmail.com

Copyright: (c) the author(s), publisher and licensee Medip Academy. This is an open-access article distributed under the terms of the Creative Commons Attribution Non-Commercial License, which permits unrestricted non-commercial use, distribution, and reproduction in any medium, provided the original work is properly cited.

\section{ABSTRACT}

Uterine prolapse during pregnancy is a rare condition in which careful assessment and management are needed to prevent complications. Here we report a case of 23-year-old gravida 3 multiparous women with a history of 2 vaginal home deliveries; she presented with uterine prolapse in active labour. She was delivered vaginally by Duhrssen's incision successfully. This case is reported to show that Duhrssen's incision can reduce the need for caesarean section in such cases.

Keywords: Uterine prolapse, Pregnancy, Duhrssen's incision

\section{INTRODUCTION}

Uterine prolapse is not expected during pregnancy. ${ }^{1,2}$ The overall incidence of prolapse in pregnancy is 1 case per 10000 to 15000 deliveries in other countries, but in India, it is as high as 1 per 547 deliveries. $^{2,3}$ In India, the incidence is high because till today a significant number of deliveries are being conducted by untrained birth attendants. There is also a trend of bearing more than two children which increases the risk of prolapse due to short consecutive pregnancies interval, which affects the supports of uterus significantly. As uterine prolapse leads to cervical desiccation, cervical oedema, cervical laceration, which leads to the non-progression of labour, and often, it leads to obstructed labour. ${ }^{4,5}$

Duhrssen's incision becomes an effective tool in such cases. ${ }^{6,7}$ This decreases the needs of caesarean section in such circumstances and thus minimises operative morbidity. But sometimes, lower uterine caesarean section needed when the head is high up with the edematous non-dilating cervix. ${ }^{8}$

\section{CASE REPORT}

We report a case of 23-year-old pregnant women belonging to lower socio-economic status as gravida 3 , para 2, presented at term pregnancy by date with uterine prolapse during active labour. She had a history of two spontaneous vaginal deliveries. Both the previous deliveries took place at home.

During the current pregnancy, she did not attend the hospital even though she recognised the prolapsed uterus three months before and reduced it herself without seeking medical help. A detailed menstrual history revealed irregularity of her menstrual cycles, and she was uncertain about the date of her last menstrual period.

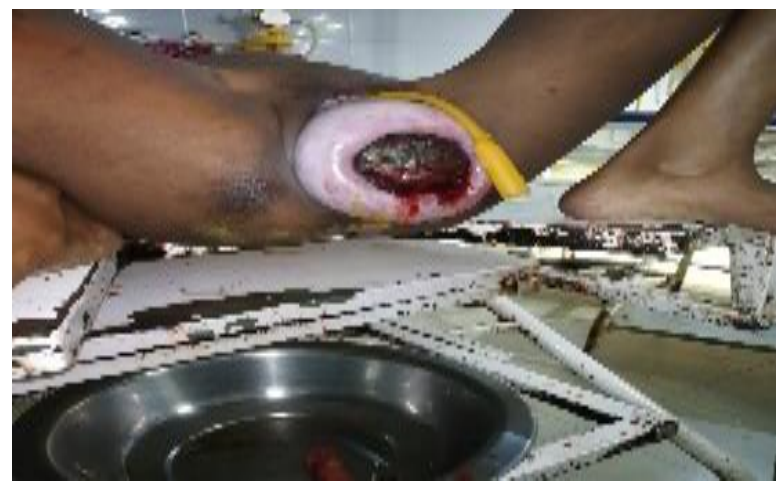

Figure 1: Cervix with lower uterine segment protruding outside introitus with entrapped head of baby. 
According to her statement, prolapse had occurred a few hours before the start of labour pain. On examination, the fetal heart sound localised four fingers above the pubic symphysis. The cervical dilatation was $5 \mathrm{~cm}$ and effacement of 50\%. Amniotic membrane was absent. The fetus was in vertex presentation. The cervix and lower uterine segment were lying outside vulva with an entrapped head of the baby as depicted in Figure 1.

Due to effective uterine contraction as well as there was no profuse cervical bleeding, and also as per patient's preference, she was planned for vaginal delivery. During the process of labour, IV drips was started with antibiotics. Strict monitoring of fetal heart sound and under proper vigilance as the labour progressed and cervix dilated enough, Duhrssen's incision at 2 o'clock position was given, and the baby delivered successfully as depicted in Figure 2. A vigorous female infant, weighing $1.7 \mathrm{~kg}$, was delivered and transferred to SCNU for better management. There was no immediate PPH. The incised area stitched with vicryl and haemostasis achieved.

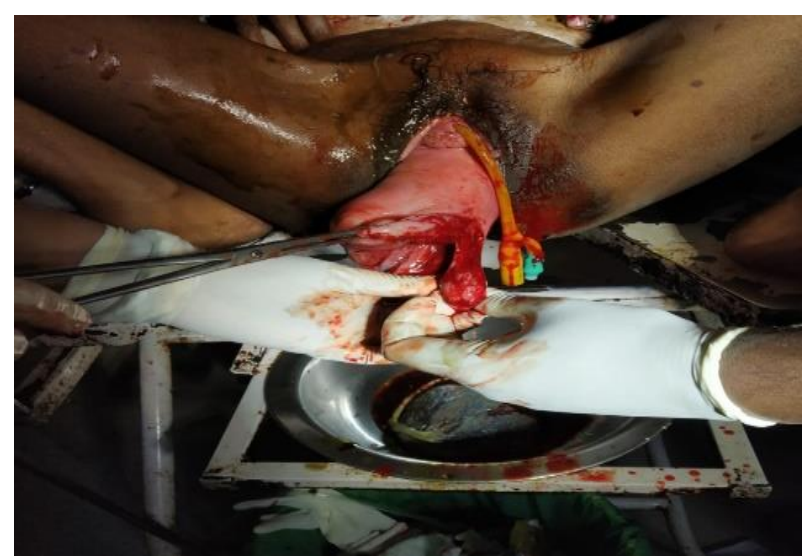

Figure 2: Delivery of baby done with Duhrssen's incision at 2 o'clock position.

Prolapse was reduced, and betadine downwash was given. Patient shifted to ward and was discharged at day 4 postpartum and was asked to perform pelvic floor Kegel's exercise. She had stage 2 POPQ uterine prolapse during discharge. The patient didn't follow up after being discharged.

\section{DISCUSSION}

Uterine prolapse is a common case in non-pregnant older women; however, uterine prolapse complicating pregnancy is a rare event which either exists before or has an acute onset during pregnancy. The risk factors of uterine prolapse during pregnancy are multifactorial. Parity, malnutrition, vaginal deliveries, short consecutive pregnancy interval and the physiological increase in cortisol and progesterone during pregnancy causes aggravation of prolapse by softening and stretching pelvis tissues. There is a four times higher risk of uterine prolapse in women with two vaginal deliveries as reported in the literature. ${ }^{9}$ In this condition, urinary obstruction and labour abnormalities are frequently seen. There is difficulty in cervical dilatation and laceration which leads to prolonged labour and cervical dystocia. In early detection of cases, conservative treatment in antenatal period in the form of bed rest, Trendelenburg position with manual reposition of prolapsed mass is recommended. If conservative management fails, laparoscopic colposuspension surgery can be done.

As in our case, the patient presented in active labour near term pregnancy, Duhrssen's cervical incision under close supervision is applied to conduct normal vaginal delivery. Duhrssen's incision is three surgical incisions on an incompletely dilated cervix corresponding roughly to 2,6 and 10 O'clock position which leads to the immediate delivery of a fetus with entrapped head. Elective caesarean section may be the safest mode, especially in cases of cervical elongation and oedema. In our case, we did not repair the prolapse as uterine fundus will return to pelvis minor within few weeks after delivery and it is reversible. Moreover, our patient did not come to the hospital for follow-up after being discharged.

\section{CONCLUSION}

Uterine prolapse in pregnancy though rare but its incidence in the Indian population is increasing due to high prevalence of risk factors. The management of uterine prolapse during labour is individualised depending on the severity of prolapse, gestational age, parity and patients' preference.

Duhrssen's incision is a very convenient and simple procedure by which delivery can be conducted vaginally and thus reduces the need of caesarean section as illustrated in our case.

\section{ACKNOWLEDGMENTS}

Authors would like to thank Dr. Gautam Choubey, Assistant Professor (senior grade), Department of Mechanical \& Aerospace Engineering, Institute of Infrastructure Technology Research and Management (IITRAM) Ahmedabad (An Autonomous Government University), Gujarat, India for writing assistance, language editing and proofreading of the article.

\section{Funding: No funding sources \\ Conflict of interest: None declared \\ Ethical approval: Not required}

\section{REFERENCES}

1. Pandey K, Arya S, Pande S. Pregnancy with uterine prolapse: Duhrssen's incision still valid in today's scenario? Int J Reprod Contracept Obstet Gynecol. 2013;2(4):586-90. 
2. Kibel I. Pregnancy at term in prolapsed uterus. Am J Obstet Gynecol. 1944;47:703-4.

3. Keettel WC. Prolapse of the uterus during pregnancy. Am J Obstet Gynecol. 1941;42:121-6.

4. Sawyer D, Frey K. Cervical prolapse during pregnancy. J Am Board Fam Pract. 1999;13(3).

5. Daskalakis G, Lymberopoulos E, Anastasakis E, Kalmantis K, Athanasaki A, Manoli A et al. Uterine prolapse complicating pregnancy. Arch Gynecol Obstet. 2007;276:391-2.

6. Ruben L, Yen C, Kristen UR, Richard LH. Vaginal Delivery After Dührssen Incisions in a Patient With Bladder Exstrophy and Uterine Prolapse. Obstet Gynecol. 2017;129(4):689-92.
7. Huber CP. Dührssen's incisions. Am J Obstet Gynecol. 1939;37:824-34.

8. Tsikouras P, Dafopoulos A, Vrachnis N, Iliodromiti Z, Bouchlarioou S, Pinidis $P$ et al. Uterine prolapse in pregnancy: risk factors, complications and management. J Matern Fetal Neonatal Med. 2014;27:297-302.

9. Cingillioglu B, Kulhan M, Yildirim Y. Extensive uterine prolapse during active labor: a case report Int Urogynecol J. 2010;21:1433-4.

Cite this article as: Chakraborty A, Gohain BS. Vaginal delivery by Duhrssen's incision in a case of uterine prolapse. Int J Reprod Contracept Obstet Gynecol 2021;10:752-4. 